\title{
Magnesium and strontium isotope fractionation during microbial dolomite formation
}

\author{
Michael Tatzel $^{1}$, Adina Paytan ${ }^{1}$, Zach A. DiLoreto ${ }^{2}$, \\ Maria Dittrich ${ }^{2}$, Tomaso R. R. Bontognali ${ }^{3}$, Mónica \\ Sánchez-Román ${ }^{4}$ \\ ${ }^{1}$ University of California Santa Cruz, CA, USA \\ (mtatzel@ucsc.edu, apaytan@ucsc.edu) \\ ${ }^{2}$ University of Toronto, Toronto, Canada \\ (zach.diloreto@utoronto.ca,mdittrich@utsc.utoronto.ca) \\ ${ }^{3}$ Space Exploration Institute, Neuchâtel, Switzerland \\ (tomaso.bontognali@space-x.ch) \\ ${ }^{4}$ Vrije Universiteit Amsterdam (m.sanchezroman@vu.nl)
}

Microbial mediation is considered an important process for the formation of primary dolomite at ambient temperature. However, in ancient sedimentary sequences, microbial dolomite cannot be discerned from dolomite that formed through a secondary replacement —or any other high temperatures abiotic processes - based on structural, mineralogical, chemical or 'traditional' stable isotope characteristics. We explore the possibility of making this distinction by characterizing stable isotope shifts of magnesium $\left(\delta^{26 / 24} \mathrm{Mg}\right)$ and strontium $\left(\delta^{88 / 86} \mathrm{Sr}\right)$ that occur during primary dolomite formation in a modern hypersaline environment in Qatar and in experimentally precipitated dolomite.

We show that the isotopic difference $\left(\Delta^{26 / 24} \mathrm{Mg}\right)$ between experimental medium and (proto-)dolomite can differ in sign and magnitude for different microbial strains including halomonas $s p$, chromohalobacter $s p$, idiomarina $s p$, halomonas $s p$ and desulfovibrio barsiliensis. This finding explains differences in $\Delta^{26 / 24} \mathrm{Mg}$ across different microbial zones in the shallow subsurface of the Khor Al-Adaid sabkhas and conforms with the wide range of $\Delta^{26 / 24} \mathrm{Mg}$ values previously observed in the sabkahs of Abu Dhabi. The shallow pore water and lagoon water $\delta^{26 / 24} \mathrm{Mg}$-values can be significantly lowered relative to typical seawater values through the simultaneous formation of authigenic clays that form close to the water-sediment interface. We tentatively suggest that this complexity makes an easy and straigthforward identification of ancient, primary dolomite based on $\delta^{26 / 24} \mathrm{Mg}$ alone complicated, but shows its potential to obtain a detailed picture of specific microbial involvement. Our prelimnary $\delta^{88 / 86} \mathrm{Sr}$ results show a systematic decrease in dolomite relative to pore water and could provide independent means to identify microbial dolomite. 